\title{
Spontaneous pneumomediastinum associated with COVID-19: Rare complication of 2020 pandemic
}

\author{
Arnaldo A Nieves-Ortiz ${ }^{1 *}$, Vanessa Fonseca-Ferrer ${ }^{1}$, \\ Kyomara Hernández-Moya ${ }^{1}$, Keren Mendez Ramirez ${ }^{2}$, Jose \\ Ayala-Rivera1, Marangely Delgado', Juan Garcia-Puebla², \\ Rosangela Fernández-Medero ${ }^{2}$ and Ricardo Fernandez- \\ Gonzalez ${ }^{2}$
}

${ }^{1}$ Internal Mericine Department, San Juan City Hospital, San Juan, PR 00935

${ }^{2}$ Pulmonary Disease and Critical Care Medicine, San Juan City Hospital, San Juan, PR 00935

\section{Abstract}

Spontaneous pneumomediastinum (SPM) is a rare condition, more commonly seen in patients with history of asthma, chronic obstructive pulmonary disease, infections, or drug users. Today, we face one novel virus that has cause an outbreak of acute respiratory illness, affecting over a million individuals worldwide. New knowledge is been gained of the virus and possible complications are been seen. Following, we present the case of a 71-year-old man with diagnosis of COVID-19 pneumonia complicated with spontaneous pneumomediastinum.

\section{More Information}

*Address for Correspondence:

Arnaldo A Nieves-Ortiz, MD, Internal Medicine Department, San Juan City Hospital, San Juan, PR 00935, Puerto Rico,

Email: nievesortizmd@gmail.com

Submitted: 02 October 2020

Approved: 16 November 2020

Published: 17 November 2020

How to cite this article: Nieves-Ortiz AA, Fonseca-Ferrer V, Hernández-Moya K, Ramirez KM, Ayala-Rivera J, et al. Spontaneous pneumomediastinum associated with COVID-19: Rare complication of 2020 pandemic. J Pulmonol Respir Res. 2020; 4: 018-020.

DOI: 10.29328/journal.jprr.1001016

Copyright: @ 2020 Nieves-Ortiz AA, et al. This is an open access article distributed under the Creative Commons Attribution License, which permits unrestricted use, distribution, and reproduction in any medium, provided the original work is properly cited.

Keywords: Spontaneous pneumomediastinum; COVID-19; Pneumonia

(A) Check for updates

OPEN ACCESS

\section{Background}

SPM or spontaneous mediastinal emphysema is a rare condition characterized by free air in the mediastinum not preceded by thoracic trauma, surgery, or any other medical procedure [1-3]. It was first described by Louis Hamman in 1939, which is why it is also known as Hamman's syndrome $[1.2,4,5]$. SPM typically presents with symptoms of pleuritic chest pain, dyspnea and cough. Upon suspicion of SPM, the goal is to evaluate for potential triggers, exclude differential diagnosis such as pneumothorax or esophageal rupture and finally evaluate for possible complications such as tension pneumomediastinum. Treatment is supportive and includes rest, analgesia and avoidance of maneuvers that may increase the pulmonary pressures. In most cases, the condition self resolves and rarely, invasive surgical intervention are required and most patient do not develop long term sequela or recurrence.

\section{Introduction}

SARS-CoV-2 disease commonly known as COVID-19, is an emerging viral infection which started in December 2019 and has become one of the world's deadliest pandemic known in history. Everyday new knowledge is acquired, on the various forms of clinical presentations and radiological changes which exist in patients infected with COVID-19. The most known radiological findings include ground glass opacities and consolidations with peripheral distribution. In approximately $1 \%$ of the cases, spontaneous pneumothorax have been identified. These findings usually serve as potential markers of COVID infection. Nevertheless, new complications are observe such as spontaneous pneumomediastinum (SPM). SPM is a rare condition characterized by free air in the mediastinum not preceded by thoracic trauma, surgery, or any other medical procedure [1-3]. It was first described by Louis Hamman in 1939, which is why it is also known as Hamman's syndrome $[1,2,4,5]$. SPM typically presents with symptoms of pleuritic chest pain, dyspnea and cough. It is unknown what is the precise mechanism of spontaneous pneumomediastinum after COVID infection, but possible mechanisms include diffuse alveolar damage secondary to a severe pneumonia. In severe pulmonary infections, repeated cough spells, increase distal airway pressure and result in increased alveolar rupture and gas leakage to the peribronchovascular intertisium that may extend to the mediastinum. Upon suspicion of SPM, the goal is to evaluate for potential triggers, exclude differential 
diagnosis such as pneumothorax or esophageal rupture and finally evaluate for possible complications such as tension pneumomediastinum. Reported cases secondary to viral infection are very rare. Further studies of SP and COVID-19 infection are needed in order to determine its role as prognostic factor or disease progression marker. Treatment for SP is mainly supportive and includes rest, analgesia and avoidance of maneuvers that may increase the pulmonary pressures. In most cases, the condition self resolves and rarely, invasive surgical intervention are required and most patient do not develop long term sequela or recurrence.

\section{Case presentation}

We present the case of a A 71-year-old man with past medical history of arterial hypertension and prostate cancer treated with 44 sessions of radiotherapy presented to the emergency room with complains of dyspnea on exertion of five (5) days of evolution. Review of systems included anorexia, nausea and diarrhea. Patient reported recent travel to the Dominican Republic. He denies fever, chills, unintentional weight loss, chest pain, or sick contacts. Medications included Nifedipine, Atenolol, Tamsulosin and Hydralazine. Vital signs remarkable for tachypnea of $30 \mathrm{bpm}$ with peripheral oxygenation of $79 \%$ at room air. Physical examination revealed notable respiratory distress and bilateral bibasilar rales.

Laboratories showed leukocytosis with lymphopenia with slight toxic granulation and normochromic normocytic anemia. Laboratory remarkable for elevated Ferritin $2617 \mathrm{ng} /$ $\mathrm{mL}$, elevated D-Dimer $24.3 \mathrm{mg} / \mathrm{L}$, elevated fibrinogen $687 \mathrm{mg} /$ $\mathrm{dL}$, central bicarbonate of $18 \mathrm{mEq} / \mathrm{l}$, hyponatremia $130 \mathrm{mEq} / \mathrm{l}$, hypochloremia of $97 \mathrm{mEq} / \mathrm{l}$, prerenal azotemia with BUN/ $\mathrm{Cr}>20$, lactate dehydrogenase of $247 \mathrm{IU} / \mathrm{L}$, and erythrocyte sedimentation rate of 64 . CXR shows parenchymal increased interstitial markings and bilateral pulmonary opacities more confluent towards the lung bases with an elongated aorta with atherosclerotic changes. Nasopharyngeal PCR swab test was positive for COVID-19 infection. Patient was treated with mechanical ventilation and lung protective ventilation, dexamethasone therapy, and IV antibiotics. After 5 days of admission, patient developed ARDS as complication of COVID-19. Chest CT (Figure 1) demonstrated bilateral diffuse areas of ground-glass opacity and consolidations, features compatible with COVID-19 pneumonia. On MICU day 28, patient developed a respiratory distress for which chest CT (Figure 2) was performed showing a significant pneumomediastinum with associated subcutaneous emphysema extending to the thoracic wall and lower neck, anterior apical pneumothorax, and cardiomegaly.

Given spontaneous pneumomediastinum was highly likely a complication of SARS-CoV 2 infection, management consisted of supportive care.

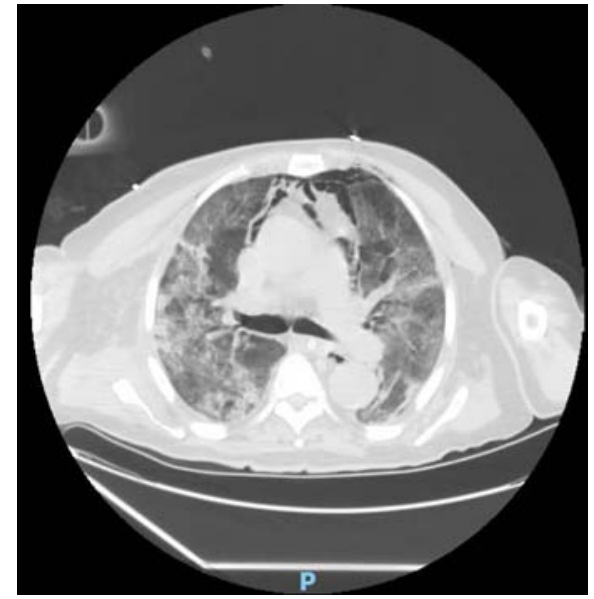

Figure 1: Lung parenchymal shows increased interstitial markings as well as peribronchial cuffing, diffuse bilateral patchy ground glass and confluent densities noted. Small pleural effusion.

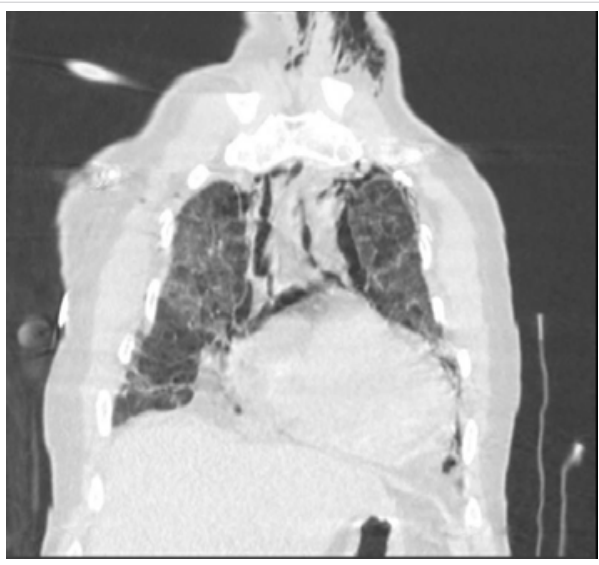

Figure 2: Diffuse pneumomediastinum and subcutaneous emphysema extending to the thoracic wall and lower neck.

\section{Conclusion}

Spontaneous pneumomediastinum is caused by a pressure gradient between the alveoli and pulmonary interstitium leading to alveolar breakdown. In cases of infection by SARS$\mathrm{CoV}$, pneumomediastinum may be related to damage and rupture of alveolar membrane caused by the virus. Although pneumomediastinum is usually considered a self-limiting condition, with an unknown precise pathological mechanism; there is limited literature resources and reports on potential complications associated with COVID-19 pneumonia, overall incidence has not yet fully well-established. It is important to highlight this possible complication of COVID-19 pneumonia, which serves an uncommon marker of worsening disease. In the era of SARS-CoV 2 pandemic, physicians need to be aware of rare and uncommon complications of this novel virus.

\section{Acknowledgment}

We will like to acknowledge the department of Pulmonary and Critical Care Fellowship Program, San Juan City Hospital. We have no conflict of interest to declare. This statement is to certify that all authors have seen and approved the manuscript being submitted. 


\section{References}

1. Gorospe L, Ayala-Carbonero A, Ureña-Vacas A, Fra Fernández $S$, Muñoz-Molina GM, et al. Spontaneous Pneumomediastinum in Patients With COVID-19: A Case Series of Four Patients. Arch Bronconeumol. 2020; 56: 754-756.

PubMed: https://www.ncbi.nlm.nih.gov/pmc/articles/PMC7535617/

2. Fishman AP, Elias JA, Fishman JA, Grippi MA, Robert M. Senior et al. Fishman's Pulmonary Disease and Disorders. 4. Philadelphia: McGraw-Hill Medical. 2008.

3. Caceres M, Ali SZ, Braud R, Weiman D, Garrett HE. Jr, et al. Spontaneous pneumomediastinum a comparative study and review of the literature. Ann Thorac Surg. 2008; 86: 962-966.

PubMed: https://pubmed.ncbi.nlm.nih.gov/18721592/

4. Sahni S, Verma S, Grullon J, Esquire A, Patel P, et al. Spontaneous pneumomediastinum time for consensus. N Am J Med Sci. 2013; 5: 460-464.

PubMed: https://pubmed.ncbi.nlm.nih.gov/24083220/
5. Ryoo JY. Clinical analysis of spontaneous pneumomediastinum. Tuberc Respir Dis (Seoul). 2012; 73: 169-173.

PubMed: https://www.ncbi.nlm.nih.gov/pmc/articles/PMC3492402/

6. Meireles J, Neves S, Castro A, França M. Spontaneous pneumomediastinum revisited. Respir Med CME. 2011; 4: 181-183. PubMed: https://www.ncbi.nlm.nih.gov/pmc/articles/PMC5474372/

7. Wegner U, Jeffery G. Spontaneous Pneumomediastinum Associated With SARS-CoV-2: Infrequent Complication of the Novel Disease. Cureus. 2020; 12: e9189.

PubMed: https://www.ncbi.nlm.nih.gov/pmc/articles/PMC7364406/

8. Al-Azzawi M, Douedi S. Spontaneous Subcutaneous Emphysema and Pneumomediastinum in COVID-19 Patients: An Indicator of Poor Prognosis? Am J Case Rep. 2020; 21: e925557.

PubMed: https://pubmed.ncbi.nlm.nih.gov/32703927/

9. Wang W, Gao R, Zheng Y, Jiang L. COVID-19 with spontaneous pneumothorax, pneumomediastinum and subcutaneous emphysema. J Travel Med. 2020; 27. taaa062.

PubMed: https://pubmed.ncbi.nlm.nih.gov/32330274/ 